\title{
Papillary Carcinoma: A Rare Cause of Cutaneous Lesion on Dorsum of Nose
}

\author{
Soumick Ranjan Sahoo ${ }^{1,2}$ Mandira Sarma ${ }^{1}$ \\ 1 ENT Department, ESIC Model Hospital, Guwahati, India \\ ${ }^{2}$ Guwahati Neurological Research Centre Hospital, Guwahati, India \\ Ann Natl Acad Med Sci (India) 2022;58:38-40.
}

Address for correspondence Soumick Ranjan Sahoo, MBBS, 4E, Tower 2, Genex Exotica, Kumarpur, G.T. Road, Asansol, Burdwan 713304, West Bengal (e-mail: soumicksahoo@gmail.com).

\author{
Abstract \\ Keywords \\ - papillary carcinoma \\ - cutaneous nodular \\ lesion of nose
}

The skin of the nose is a common site for various benign and malignant lesions. Herein, we report a cutaneous nodular lesion on the dorsum of the nose in an 80-year-old female, which was surgically excised under local anesthesia. On histopathological examination, she was diagnosed with papillary carcinoma, a very rare disorder at such a location. The patient was followed-up and no recurrence was noted.

\section{Introduction}

The nose is an exposed and highly visible area of the face. Therefore, cutaneous lesions of nose are very easily noticed by the patients themselves and other people. The high concentration of sebaceous glands, increased ultraviolet radiation exposure, and genetic abnormalities account for the various benign and malignant cutaneous lesions of the nose such as rhinophyma, hemangioma, squamous cell carcinoma, melanoma, basal cell carcinoma, etc. ${ }^{1}$

Papillary carcinoma, also known as digital papillary adenocarcinoma, is a rare tumor of the sweat glands, which is mainly localized to the digits. The presence of such a lesion in the face is very rare. Herein, we report a cutaneous nodular lesion on the dorsum of the nose, which was surgically excised. On histopathological examination, the patient was diagnosed with papillary carcinoma. The case is presented in view of its rarity.

\section{Case History}

An 80-year-old female patient presented to the ENT OPD with a painless growth on the dorsum of the nose since 2 years, which was insidious in onset. It was initially small and had progressively increased to its present size. There was no history of trauma or any other swelling in other parts of the body. There was no history of weight loss or loss of appetite. On local examination, a large solitary, solid, irregular-shaped, nodular, pinkish red colored growth was noted on the dorsum of the nose. The growth was about $4 \times 5 \mathrm{~cm}$ in size, nontender, firm in consistency, with well-defined edges, had restricted mobility, and did not bleed on touch (-Fig. 1). Anterior rhinoscopy examination did not reveal any abnormality. Diagnostic nasal endoscopy was done, and no abnormalities were noted. Paranasal sinus examination was within normal limits. There was no palpable lymphadenopathy. Rest of the ENT examination was within normal limits. Preoperative blood investigations and chest X-ray were done, and COVID-19 reverse transcriptase polymerase chain reaction (RTPCR) test was done, which was negative. Wide excision of lesion was performed, taking a $1 \mathrm{~cm}$ healthy margin, and primary closure was done. The excised specimen was sent for histopathology examination, which gave a diagnosis of papillary carcinoma (- Figs. 2 and $\mathbf{3}$ ). Patient was followed-up for 8 months ( - Fig. 4 ) and no recurrence was noted.

\section{Discussion}

Papillary carcinoma is a rare malignant tumor of sweat glands, which is usually located on the digits. It is also known published online November 5, 2021
DOI https://doi.org/ 10.1055/s-0041-1736504. ISSN 0379-038X.

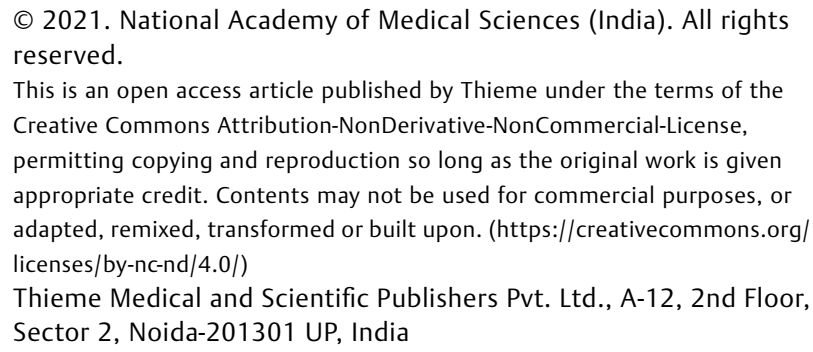

This is an open access article published by Thieme under the terms of the Creative Commons Attribution-NonDerivative-NonCommercial-License, permitting copying and reproduction so long as the original work is given appropriate credit. Contents may not be used for commercial purposes, or adapted, remixed, transformed or built upon. (https://creativecommons.org/ licenses/by-nc-nd/4.0/)

Thieme Medical and Scientific Publishers Pvt. Ltd., A-12, 2nd Floor, Sector 2, Noida-201301 UP, India 


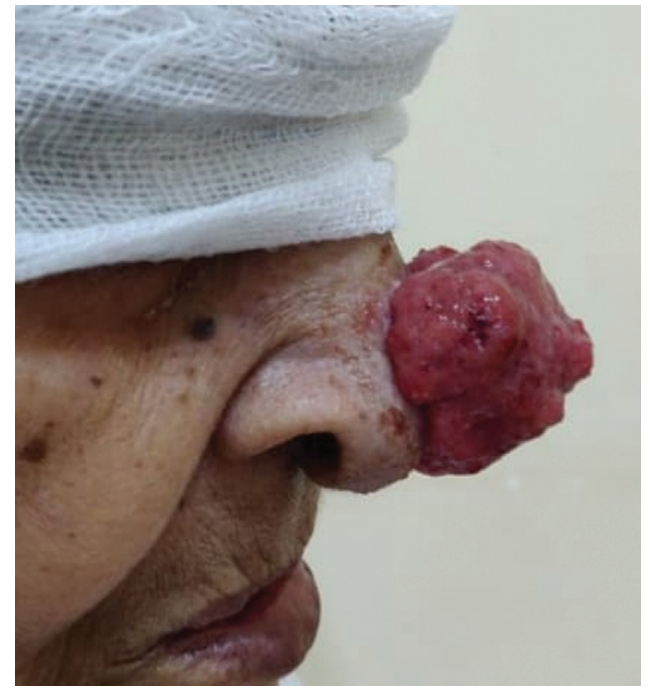

Fig. 1 Preoperative clinical picture.

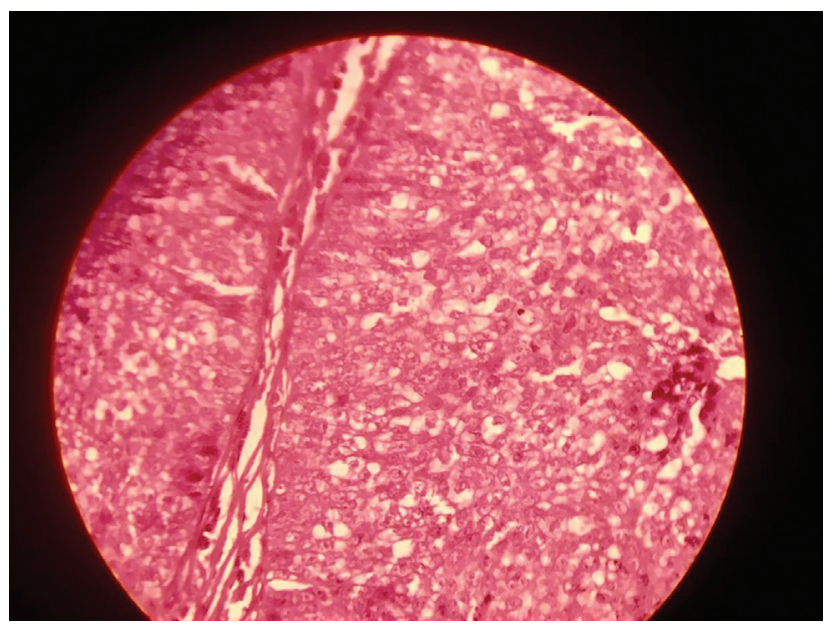

Fig. 2 (40x hematoxylin and eosin $[H \& E])$.

by the term digital papillary adenocarcinoma. It is a rare neoplasm of the eccrine sweat gland cells.

The primary tumor commonly presents as a slow-growing solitary mass, usually between the nail bed and distal interphalangeal joint. ${ }^{2}$ There were few instances of cases being reported at unusual sites such as the lips and ears ${ }^{3}$.In our case, the lesion was also located at an atypical location on the dorsum of nose, presenting as a nodular growth.

The tumor has an aggressive course in terms of local invasion, with a $14 \%$ chance of metastasis. ${ }^{2}$ The most common site for metastasis is lung, whereas lymph nodes, brain, skin, bones, and kidneys are the other sites. ${ }^{3}$ In our case, there were no finding of pulmonary metastasis on chest X-ray.

As the tumour has a high-recurrence rate, the recommended treatment is one of wide local excision of the primary tumor, but no objective margin is defined in the literature. $^{2,4}$ There were few reports in which Mohs mi-

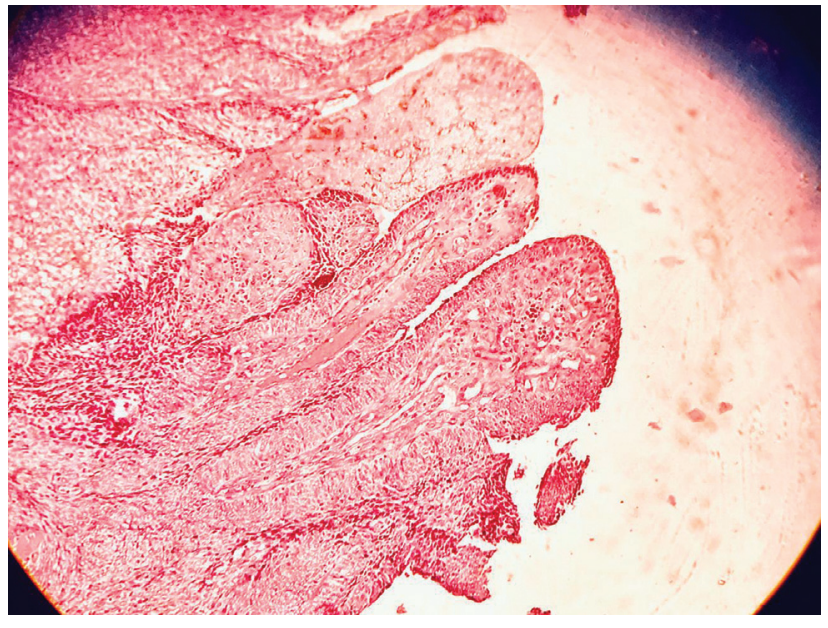

Fig. 3 (10x lower power hematoxylin and eosin [H\&E]). Sections show a solid to cystic tumor arranged in lobules with focal papillary projections. The tumor cells are highly pleomorphic, oval to polygonal in shape with vesicular chromatin, and prominent nucleoli. Variable amount of bubbly cytoplasm with vacuoles is seen. Focal areas of necrosis and lymphoid aggregation is noted. The tumor is limited to surface and papillary dermis.

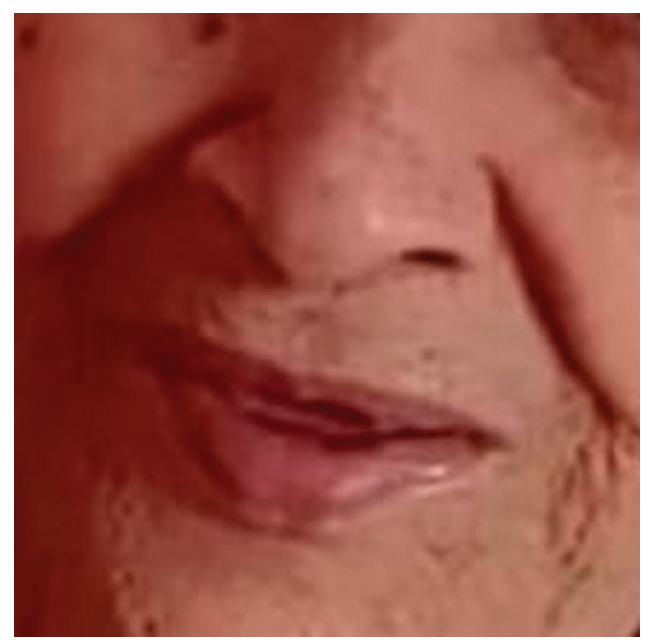

Fig. 4 Postoperative follow-up image at 8 months.

crographic surgery was performed as excision after punch biopsy $^{4,5}$ and as a reexcision procedure ${ }^{6}$.

Sentinel node biopsy may be done for staging of the tumor to potentially identify patients who may avail benefit of lymph node dissection thereafter ${ }^{7,8}$

There is no evidence available to support the use of positron emission tomography (PET) imaging, chemotherapy, or radiotherapy. ${ }^{2,8}$

Confirmation of the diagnosis is by histopathology. The characteristic histologic features include tubuloalveolar and ductal structures, with areas of papillary projections protruding into cystic lumina. The stroma varied from thin fibrous septae to areas of dense hyalinized collagen.

Close patient follow-up is recommended for all such cases of papillary carcinoma. We have followed-up the case for 8 months and no recurrence has been noted. 


\section{Conclusion}

Lesions such as papillary carcinoma are rare differential diagnosis of cutaneous lesions on the dorsum of the nose but should always be kept in mind while evaluating such lesions

\section{Ethical Approval}

The study followed the ethical guidelines of the Declaration of Helsinki. Written informed consent was taken from the patient for publication in the journal.

\section{Conflict of Interest}

None declared.

\section{References}

1 Sand M, Sand D, Thrandorf C, Paech V, Altmeyer P, Bechara FG. Cutaneous lesions of the nose. Head Face Med 2010;6:7
2 Duke WH, Sherrod TT, Lupton GP. Aggressive digital papillary adenocarcinoma (aggressive digital papillary adenoma and adenocarcinoma revisited). Am J Surg Pathol 2000;24(06):775-784

3 Gorva AD, Mohil R, Srinivasan MS. Aggressive digital papillary adenocarcinoma presenting as a paronychia of the finger. J Hand Surg [Br] 2005;30(05):534

4 Suchak R, Wang W-L, Prieto VG, et al. Cutaneous digital papillary adenocarcinoma: a clinicopathologic study of 31 cases of a rare neoplasm with new observations. Am J Surg Pathol 2012;36(12): 1883-1891

5 Bryant JR, Gardner P, Yousif M, Pui JC, Hajjar RT, Haass EA. Aggressive digital papillary adenocarcinoma of the hand presenting as a felon. Case Rep Orthop 2017;2017:6456342

6 Kao GF, Helwig EB, Graham JH. Aggressive digital papillary adenoma and adenocarcinoma. A clinicopathological study of 57 patients, with histochemical, immunopathological, and ultrastructural observations. J Cutan Pathol 1987;14(03):129-146

7 Malafa MP, McKesey P, Stone S, Dudley-Walker S, Cockerell CJ. Sentinel node biopsy for staging of aggressive digital papillary adenocarcinoma. Dermatol Surg 2000;26(06):580-583

8 Kantrow SM, Stumph JF, Zanolli MD, Wright JEA. A 46-year-old man with an enlarging finger nodule. Arch Pathol Lab Med 2005; 129(08):e179-e180 